\title{
Constitutive IL-10 Expression by Lung Inflammatory Cells and Risk for Bronchopulmonary Dysplasia
}

\author{
ARLENE GARINGO, LINDA TESORIERO, ROWENA CAYABYAB, MANUEL DURAND, MARTIN BLAHNIK, \\ SMEETA SARDESAI, RANGASAMY RAMANATHAN, CRAIG JONES, KENNY KWONG, CHANGGONG LI, \\ AND PARVIZ MINOO
}

Division of Neonatology, Department of Pediatrics, Women's \& Children's Hospital, Keck School of Medicine, University of Southern California, Los Angeles, California, 90033

\begin{abstract}
Expression of IL-10 is decreased in lungs of preterm infants. We determined the constitutive and lipopolysaccharide (LPS)-induced IL-10 synthesis by lung inflammatory cells from preterm and term infants and examined their relationship to gestational age and/or incidence of bronchopulmonary dysplasia (BPD). A total of 37 infants; preterm neonates at gestational ages of 23-27 wk (group 1); 28-34 wk (group 2), and four full-term infants with meconium aspiration (group 3) were enrolled. One sample of lung inflammatory cells, obtained during postnatal d 1-3, and another during postnatal d 4-7 were cultured in vitro in presence or absence of $100 \mu \mathrm{g} / \mathrm{mL}$ of LPS. Secreted IL-10 was measured by ELISA. A positive relationship was found between gestational age and LPSinduced, but not constitutive IL-10 production within $1-3 \mathrm{~d}$ of life; group 1 on d 1-3 had a significant number of IL-10 nonresponders compared with group 2. All term neonates in group 3 had positive LPS-induced IL-10 response. Thus, in utero maturation of IL-10 gene expression is due to acquisition of inducibility. In contrast, constitutive IL-10 production within d 1-3 of life correlated with, and predicted the incidence of BPD in the highly vulnerable very premature infants. (Pediatr Res 61: 197-202, 2007)
\end{abstract}

$\mathrm{B}^{\mathrm{P}}$ PD occurs in nearly $30 \%$ of very premature neonates born at 23-28 wk of gestation and weighing $<1000 \mathrm{~g}(1)$. The clinical phenotype of BPD in these neonates differs from that described in the 1970s as classical BPD (2). The "new" BPD is characterized by alveolar and vascular hypoplasia (3). It is currently thought that lung injury arising from positive pressure ventilation, oxygen toxicity, and pre- and postnatal infections interferes with normal alveolar development. We have proposed that the cellular underlying mechanism by which the effects of mechanical and chemical (i.e. oxygen) insults are translated into physiologic injury is inflammation. Pro-inflammatory cytokines are found in cells recovered from the lungs of premature infants at the time of intubation (4). In contrast, little if any IL-10 protein or mRNA is detectable in the same samples. Both mRNA and protein for IL-10 are readily detectable in samples from term newborns.

Received July 19, 2006; accepted September 29, 2006.

Correspondence: Parviz Minoo, Ph.D., Department of Pediatrics, Women's \& Children's Hospital, LAC + USC Medical Center, 1801 E. Marengo Street, Rm 1G1, Los Angeles, CA 90033; e-mail: minoo@usc.edu

Supported by the Hastings Foundation and National Institutes of Health, National Heart, Lung, and Blood Institute.

DOI: $10.1203 /$ pdr.0b013e31802d8a1c
IL-10 is a multifunctional cytokine that plays major roles in many aspects of the immune response. IL-10 is produced by several cell types, including T lymphocytes, monocytes, macrophages, and B cells. Upon binding to a tetrameric complex of two receptors (5), IL-10 generates signals through the JAK1-STAT3 pathway and activates the SOCS-3 gene (suppressor of cytokine signaling-3) (6). The impact of IL-10 can be partly explained by an inhibitory effect on the transcription factor nuclear factor-kappaB (NF- $\kappa \mathrm{B})$ (7). In normal healthy human sera or inflammatory cells, little to no IL-10 is detectable. However, under pathologic conditions, IL-10 production is stimulated. It is thought that the primary function of IL-10 is to limit and terminate the inflammatory responses, block the proinflammatory cytokine secretion, and regulate differentiation and proliferation of immune cells (8).

Well-controlled studies utilizing inflammatory cells isolated from the TAF of preterm neonates, cultured ex vivo, and stimulated with LPS showed quantifiable differences between the ability of immature lung inflammatory cells to produce pro-inflammatory cytokines TNF- $\alpha$ and IL- $1 \beta$, compared with IL-10 (9). These studies established three important points. First, the ability to induce pro-inflammatory cytokines such as TNF- $\alpha$ is nearly identical between preterm and term neonatal lung inflammatory cells. Second, production of IL-10 by lung inflammatory cells from preterm newborns is significantly reduced or absent when compared with term neonates, and, third, despite changes in the profile of cells recoverable from the TAF of newborns of various gestational and postnatal ages, the predominant cell type responsible for production of either TNF- $\alpha$ or IL-10 was the lung macrophage (9). Based on these results, we proposed a model by which an imbalance between the ability to produce pro- versus anti-inflammatory cytokines, which provides for a pro-inflammatory environment in the lung, may lead to presence of smoldering inflammation that contributes to pathogenesis of BPD. An important and testable prediction of this model is that reduced or absent production of IL-10 by lung inflammatory cells is associated with increased risk for BPD.

In this study, we tested the validity of the above model by examining "constitutive" and "inducible" IL-10 gene expres-

Abbreviations: BPD, bronchopulmonary dysplasia; BW, birth weight; GA, gestational age; LPS, lipopolysaccharides; TAF, tracheal aspirate fluid 
Table 1. Patient demographics

\begin{tabular}{lccc}
\hline \multicolumn{1}{c}{ Characteristics } & $\begin{array}{c}\text { Group 1 } \\
23-27 \mathrm{wk}\end{array}$ & $\begin{array}{c}\text { Group 2 } \\
28-34 \mathrm{wk}\end{array}$ & $\begin{array}{c}\text { Group 3 } \\
\text { Term }\end{array}$ \\
& $n=19$ & $n=14$ & $n=4$ \\
\hline GA (wk) & 25 & 28 & 39 \\
BW (g) & 722 & 1399 & 3535 \\
Male & $13(72 \%)$ & $9(64 \%)$ & $2(50 \%)$ \\
SGA/IUGR & $4(22 \%)$ & $1(7 \%)$ & 0 \\
Antenatal steroids & $13(72 \%)$ & $10(71 \%)$ & 0 \\
Chorioamnionitis & $10(56 \%)$ & $3(21 \%)$ & $2(50 \%)$ \\
Emergency C-section/fetal distress & $4(22 \%)$ & $3(18 \%)$ & $2(50 \%)$ \\
Days intubated & 38 & 9 & 7 \\
Doses of surfactant & 31 & 1 & 1 \\
Days on O ${ }_{2}$ & 80 & 35 & 15 \\
Steroids for BPD & $11(61 \%)$ & $2(14 \%)$ & 0 \\
BPD & $12(67 \%)$ & $2(14 \%)$ & 0 \\
\hline
\end{tabular}

SGA, small for gestational age; IUGR, intrauterine growth retardation.

sion in lung inflammatory cells from premature and term infants. We examined potential association of IL-10 gene expression with either GA (development) or incidence of BPD. The results show a significant association between constitutive and not inducible IL-10 gene expression and risk for BPD. Of interest, IL-10 inducibility was firmly associated with GA.

\section{MATERIALS AND METHODS}

Patients. This prospective study was approved by the Institutional Review Board of the University of Southern California, Keck School of Medicine. Because the study used materials that would otherwise be discarded, informed consent was not required. Summary of the patient characteristics is presented in Table 1. All infants required mechanical ventilation for respiratory failure, and were admitted to the neonatal intensive care unit at Women's \& Children's Hospital of Los Angeles County and USC Medical Center in Los Angeles, California. Twenty-three preterm infants received antenatal steroids for lung maturation. All preterm neonates received antibiotics, surfactant, and indomethacin. Infants with proven sepsis (positive blood culture) perinatal asphyxia, or major congenital anomalies were excluded. BPD was defined as dependence on supplemental oxygen to maintain "satisfactory" oxygen saturation (pulse oximeter oxygen saturation $\geq 90 \%$ ) beyond 36 wk completed gestation (10).

Tracheal fluid collection. TAF was collected only when clinically indicated as part of the routine suctioning of the endotracheal tube according to standardized protocols. Cardiopulmonary monitoring was continuous during the procedure. Inspired oxygen was increased before suctioning. Our standardized procedure for suctioning has been published before (4). TAF were collected at two time points: within $24-72 \mathrm{~h}$ of delivery (sample 1) and postnatal d 4-7 (sample 2). Many infants had two or more TAF obtained in either time period. Mean values were taken as a single value within that time period. Some infants were extubated before the collection of sample 2; their sample 1 data were included in the analysis.

Cell suspension preparation. TAF was obtained, placed on ice, and transported to the laboratory. Specimens were processed within $1 \mathrm{~h}$. Aspirate was centrifuged at $1000 \mathrm{rpm}$ for $10 \mathrm{~min}$. Cell pellets were resuspended in RPMI supplemented with $1 \%$ fetal bovine serum, $2 \mathrm{mM}$ L-glutamine, and 100 $\mathrm{U} / \mathrm{mL}$ penicillin and $100 \mu \mathrm{g} / \mathrm{mL}$ streptomycin. Absolute cell counts were determined for each TAF sample. TAF with $<1 \times 10^{5}$ cells $/ \mathrm{mL}$ were discarded. Most TAF yielded sufficient numbers to establish at least two cell culture samples of approximately $5-10 \times 10^{5}$ cells per milliliter of media. One sample was used for LPS stimulation (inducible) and the other for constitutive analysis of IL-10. All IL-10 concentrations were expressed as picograms of protein per $5 \times 10^{5}$ cells $/ \mathrm{mL}$. Cell culture and LPS (final concentration of $100 \mathrm{ng} / \mathrm{mL}$ ) treatment were according to previously described procedure (9). Cell culture supernatants were frozen at $-80^{\circ} \mathrm{C}$ in preparation for ELISA analyses.

Cytokine analysis. IL-10 and IL-8 in cell-free supernatants were determined by commercially available ELISA Kits (Quantikine, R \& D Systems, Minneapolis, MN). Supernatants were analyzed in duplicate. The values from the duplicate samples were nearly identical. The ELISA kits had a minimum detectable concentration of $7.9 \mathrm{pg} / \mathrm{mL}$ for IL-10 and $10 \mathrm{pg} / \mathrm{mL}$ for IL-8. ELISA readings on control samples without cells (RPMI only) extrapolated
Table 2. 23-27 wk gestation: group 1 (IL-10 in pg/500,000 cells)

\begin{tabular}{|c|c|c|c|c|}
\hline \multirow[b]{3}{*}{ Patient } & \multicolumn{4}{|c|}{$\mathrm{BPD}(-)(n=6)$} \\
\hline & \multicolumn{2}{|c|}{ Sample 1} & \multicolumn{2}{|c|}{ Sample 2} \\
\hline & Constitutive & LPS induced & Constitutive & LPS induced \\
\hline $1 \mathrm{~A}$ & 4.1 & 4.5 & 2.3 & 2.5 \\
\hline 1B & 1.6 & 1.8 & 0 & 0 \\
\hline $1 \mathrm{C}$ & 0 & (3.1) & 3.3 & 3.0 \\
\hline $1 \mathrm{D}$ & 0 & 0 & Extubated & \\
\hline $1 \mathrm{E}$ & 11.8 & 15.4 & 0 & (15.4) \\
\hline $1 \mathrm{~F}$ & 0 & (3.4) & 0 & (19.1) \\
\hline \multicolumn{5}{|c|}{$\operatorname{BPD}(+)(n=12)$} \\
\hline $1 \mathrm{G}$ & 0 & (3.4) & 0 & 0 \\
\hline $1 \mathrm{H}$ & 0 & 0 & 0 & 0 \\
\hline $1 \mathrm{I}$ & 5.9 & $(34.5)$ & 0 & (5.6) \\
\hline $1 \mathrm{~J}$ & 0 & 0 & 0 & 0 \\
\hline $1 \mathrm{~K}$ & 0 & 0 & 3.2 & (13.5) \\
\hline $1 \mathrm{~L}$ & 0 & 0 & 0 & 0 \\
\hline $1 \mathrm{M}$ & 0 & 0 & 53.6 & $(81.1)$ \\
\hline $1 \mathrm{~N}$ & 0 & 0 & 0 & $(9.7)$ \\
\hline 10 & 0 & 0 & 0 & 0 \\
\hline $1 \mathrm{P}$ & 0 & 0 & 0 & 0 \\
\hline $1 Q$ & 0 & 0 & 0 & 0 \\
\hline $1 \mathrm{R}$ & 0 & (2.6) & 0 & (157) \\
\hline $1 \mathrm{~S}$ & 0 & 0 & 0 & (4.7) \\
\hline
\end{tabular}

on the standard curve to an average reading of $3.9 \mathrm{pg} / \mathrm{mL}$ of IL-10. Therefore, this value (background) was subtracted from all IL-10 measurements and data points below the minimal detectable concentrations were given a value of "zero." Cytokine concentrations were expressed per $5 \times 10^{5}$ cells. As a consequence, some values which in the original measurement were above 7.9 are unexpectedly small when adjusted for cell number (e.g. patient $1 \mathrm{~B}$ in Table 2). IL-10 concentrations above threshold in the control condition (unstimulated, non-LPS-treated) were defined as constitutive production of IL-10. A positive response to LPS was a noted 50\% increase in IL-10 concentration over the control, unstimulated values. To detect IL-8 within the limits of standard curve, supernatants required 50-fold dilution (11).

Statistical analysis. Inter- and intragroup differences in IL-10 response to LPS at the specific time periods were analyzed by two-tailed $t$ tests (independent and paired samples) or with Mann-Whitney $U$ test and Wilcoxon signed-ranks test where appropriate. Pearson $\chi^{2}$ and Fisher's exact test, where appropriate, were used to assess LPS responsiveness with regards to GA and postnatal age. Pearson $\chi^{2}$ and Fisher's exact test were used to determine whether LPS responsiveness was associated with BPD. A $p$ value of $<0.05$ was considered statistically significant.

\section{RESULTS}

Thirty-seven mechanically ventilated patients were enrolled in this study. Thirty-three neonates were premature, with median GA of 27 wk (range, 23-34 wk) and mean BW of $1040 \mathrm{~g}$ (range, $473-2200 \mathrm{~g}$ ). Of the 33 preterm infants, 15 subsequently developed BPD. Two premature neonates died postnatally due to extreme prematurity. Six premature neonates were extubated before obtaining sample 2. Four intubated term neonates with meconium aspiration were used as reference. None of the infants received postnatal corticosteroids during the first week of life for prevention or treatment of BPD. A summary of the patient characteristics is presented in Table 1. Group 1 consisted of 19 patients with median GA of 25 wk (range, 23-27 wk) and mean BW of 722 g. Group 2 consisted of 14 patients with median GA of 29 wk (range, 28-34 wk) and mean BW of $1399 \mathrm{~g}$. The four term neonates comprise group 3, with median GA of $39 \mathrm{wk}$ and mean BW of 
Table 3. 28-34 wk gestation: group 2 (IL-10 in pg/500,000 cells)

\begin{tabular}{|c|c|c|c|c|}
\hline \multirow[b]{3}{*}{ Patient } & \multicolumn{4}{|c|}{$\operatorname{BPD}(-)(n=12)$} \\
\hline & \multicolumn{2}{|c|}{ Sample 1} & \multicolumn{2}{|c|}{ Sample 2} \\
\hline & Constitutive & LPS induced & Constitutive & LPS induced \\
\hline $2 \mathrm{~A}$ & 0 & 0 & Extubated & \\
\hline $2 \mathrm{~B}$ & 0 & (1.7) & 29.1 & (178.4) \\
\hline $2 \mathrm{C}$ & 0 & 0 & 19.0 & $(42.4)$ \\
\hline $2 \mathrm{D}$ & 0 & 0 & 2.6 & (31.6) \\
\hline $2 \mathrm{E}$ & 1.3 & (15.3) & Extubated & \\
\hline $2 \mathrm{~F}$ & 0 & $(12.3)$ & 0 & (2.0) \\
\hline $2 \mathrm{G}$ & 0 & 0 & 0 & $(33.5)$ \\
\hline $2 \mathrm{H}$ & 1.6 & 0 & Extubated & \\
\hline $2 \mathrm{I}$ & 0 & 0 & Extubated & \\
\hline $2 \mathrm{~J}$ & 0 & $(22.4)$ & 0 & $(82.3)$ \\
\hline $2 \mathrm{~K}$ & 0 & $(4.8)$ & 2.2 & (75.6) \\
\hline $2 \mathrm{~L}$ & 0 & (20) & Extubated & \\
\hline \multicolumn{5}{|c|}{$\operatorname{BPD}(+)(n=2)$} \\
\hline $2 \mathrm{M}$ & 0 & 0 & 18.9 & (122.7) \\
\hline $2 \mathrm{~N}$ & 4.0 & 2.8 & 65.7 & (138.0) \\
\hline
\end{tabular}

Table 4. Term neonates: reference group (IL-10 in pg/500,000 cells)

\begin{tabular}{cccccc}
\hline & \multicolumn{2}{c}{ Sample 1 } & & \multicolumn{2}{c}{ Sample 2 } \\
\cline { 2 - 3 } \cline { 5 - 6 } Patient & Constitutive & LPS induced & & Constitutive & LPS induced \\
\hline 3A & 8.90 & $(15.0)$ & & 9.0 & $(91.6)$ \\
3B & 1.5 & $(25.4)$ & & 4.5 & 4.3 \\
3C & 11.2 & $(23.5)$ & & 12.3 & $(75.6)$ \\
3E & 8.3 & $(33.6)$ & & 6.5 & $(45.7)$ \\
\hline
\end{tabular}

3535 g. During the study period, 112 TAF were obtained, 72 of which were analyzed by the ex vivo culture system.

“Constitutive" IL-10 production by lung inflammatory cells. We arbitrarily defined ELISA-detectable levels of IL-10 production by lung inflammatory cells in the absence of LPS stimulation as "constitutive." Thus, $22 \%$ or $4 / 18$ neonates in group 1 (Table 2, patients $1 \mathrm{~A}, 1 \mathrm{~B}, 1 \mathrm{E}$, and 1I) and $21 \%$ or $3 / 14$ neonates in group 2 (Table 3 , patients $2 \mathrm{E}, 2 \mathrm{H}$, and $2 \mathrm{~N}$ ) exhibited constitutive IL-10 production within the first $3 \mathrm{~d}$ of life (sample 1). In sample 2 (d 4-7 of life), the number, and not the identity of the neonates with constitutive IL-10 production in group 1 remained the same (Table 2, patients $1 \mathrm{~A}$, $1 \mathrm{C}, 1 \mathrm{~K}$, and $1 \mathrm{M})$. In contrast, the number of patients in group 2 with constitutive IL-10 in sample 2 doubled to six (Table 3, patients $2 \mathrm{~B}, 2 \mathrm{C}, 2 \mathrm{D}, 2 \mathrm{~K}, 2 \mathrm{M}$, and $2 \mathrm{~N}$ ) out of nine neonates or $66 \%$. In contrast to the preterm neonates, all four infants born at term showed constitutive production of IL-10 by lung inflammatory cells at both time periods of sampling (Table 4).

"Inducible" IL-10 production by lung inflammatory cells. As above, we arbitrarily defined as "inducible," an IL-10 production level in response to LPS, that exceeded by $\geq 50 \%$, the "constitutive" level of IL-10 production by cells derived from the same TAF sample. Accordingly, five preterm neonates in group 1 (Table 2, patients $1 \mathrm{C}, 1 \mathrm{~F}, 1 \mathrm{G}, 1 \mathrm{I}$, and $1 \mathrm{R}$ ) showed production of inducible IL-10, with various magnitudes, in response to LPS on d 1-3 of life. This number on d 4-7 of life (sample 2) for group 1 increased to 8 (Table 2, patients $1 \mathrm{E}, 1 \mathrm{~F}, 1 \mathrm{I}, 1 \mathrm{~K}, 1 \mathrm{M}, 1 \mathrm{~N}, 1 \mathrm{R}$, and $1 \mathrm{~S})$. For group 2, inducible IL-10 in sample 1 was found in six patients (Table 3 , patients $2 \mathrm{~B}, 2 \mathrm{E}, 2 \mathrm{~F}, 2 \mathrm{~J}, 2 \mathrm{~K}, 2 \mathrm{~L})$. In the same group, the number of inducible IL-10 samples on d 4-7 of life increased to 9 , or $100 \%$ of neonates who remained intubated. With the exception of one neonate on d 4-7 of life (patient B) all four term neonates exhibited robust IL-10 induction in response to LPS (Table 4).

LPS-stimulated IL-8 production as a control. Presence or absence of IL-8 was measured in every sample in which neither "constitutive" nor "inducible" IL-10 was found (i.e. samples with a value of " 0 " in Tables 2,3 , and 4) to rule out cell death and other artifacts. With the exception of one patient, 1H in Table 2, IL-8 was found in all samples tested, verifying both viability of the TAF-derived inflammatory cells and functionality of the LPS-induced signal transduction pathway (data not shown).

\section{DISCUSSION}

We report new information on the relationship between IL-10 and BPD in preterm neonates. In neonates born prematurely between 23 and $27 \mathrm{wk}$ of gestation, $91.7 \%$ of the infants without detectable constitutive IL-10 developed BPD, compared with $50 \%$ of those with positive IL-10 values. This observation suggests a strong inverse relationship between the risk for BPD and constitutive production of a key immunoregulatory cytokine, IL-10.

Overall we examined two aspects of IL-10 gene expression in a mixed population of inflammatory cells from three cohorts of neonates and correlated the results with incidence of BPD. First, we measured the production and secretion of "constitutive" IL-10 by lung inflammatory cells in culture without stimulation. This approach measures IL-10 levels that presumably reflect a gene expression pattern similar or identical to the in vivo conditions. Concurrently, we also assessed the "inducibility" of IL-10 production and secretion in response to LPS stimulation. In adults, and not infants, interindividual variabilities in both LPS-induced and constitutive IL-10 production and secretion have been previously recognized $(12,13)$.

Because IL-10 was not expressed by lung inflammatory cells from the majority of preterm infants of 23-34 wk of gestation, we examined the induction of IL-8, which served two purposes. First, although we routinely examined cell viability by the trypan blue exclusion assay, the use of IL-8 measurement was a more precise verification of whether the cells were functionally viable through the $24 \mathrm{~h}$ of culture. This criterion identified the patient designated $1 \mathrm{H}$ (Table 2), who did not show an LPS-induced IL-8 response and was therefore eliminated from subsequent analyses. The second purpose of IL-8 was related to the functionality of the LPS-stimulated signal transduction pathway. LPS is an established activator of the signal transduction pathway that results in activation of NF-kB and production of pro- and anti-inflammatory cytokines (14). Thus, IL-8 production verifies that the LPSactivated signal transduction pathway is intact and functional.

$I \boldsymbol{L}-10$ and BPD. To determine which aspect of IL-10 correlates with BPD, we compared the incidence of constitu- 

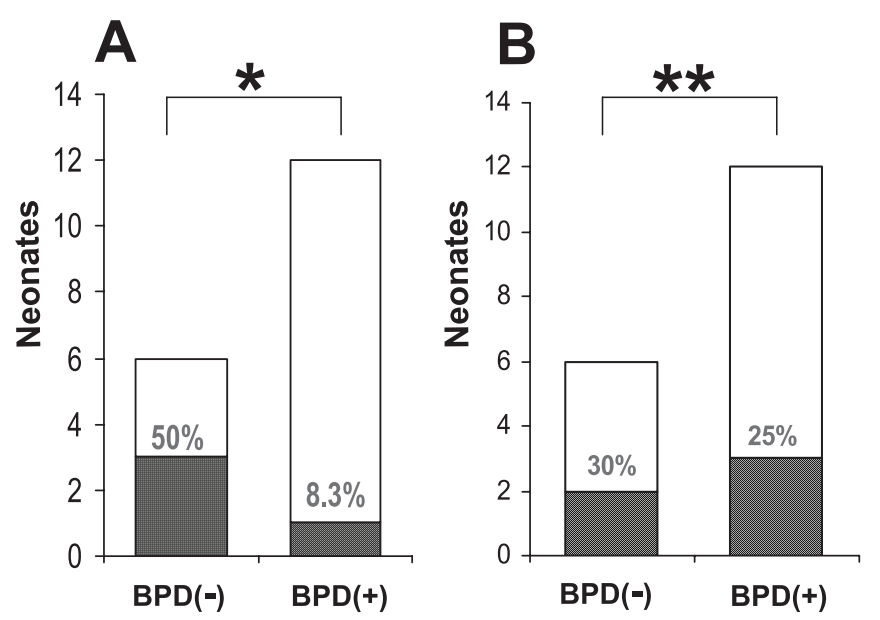

Figure 1. IL-10 gene expression in sample 1 of neonates in group 1 derived from data in Table 2. (A) Constitutive IL-10. (B) Inducible IL-10. * $p=0.05$, $* * p=0.71$.

tive and inducible IL-10 in neonates who developed BPD versus those who did not (Tables 2 and 3). The premature infants in group 1 are most vulnerable, and the incidence of BPD is reported to approach $70 \%$ (1). Consistent with these data, the incidence of BPD in our cohort of 18 neonates was $66 \%$. In the newborns without BPD [BPD (-)], the incidence of constitutive IL-10 expression in sample 1 was $50 \%$ (Fig. $1 A)$. In contrast, this value in newborns who developed BPD [BPD $(+)]$ was a mere $8.3 \%\left(p<0.05\right.$ (Pearson $\chi^{2}$ or 0.083 by Fisher's exact test). These results clearly indicate a significant association between presence of constitutive IL-10 within the first $3 \mathrm{~d}$ of life and the risk for BPD.

In contrast, we found no association between the incidence of inducible IL-10 and the risk for BPD. In group 1 infants who did not develop BPD (Table 2), the incidence of inducible IL-10 was $30 \%$ (Fig. 1B). This was in contrast to an incidence of $25 \%$ in the group of neonates with BPD (Table 2). The $p$ value for the differences between the two groups was not significant $(p=0.71)$.

Examination of constitutive and inducible IL-10 in sample 2 from neonates in group 1 was also conducted. Here, the incidence of both inducible and constitutive IL-10 production was $40 \%$ in patients who remained intubated but did not develop BPD (Table 2). In this group, one patient, 1D, was extubated before collection of sample 2. In neonates with $\mathrm{BPD}$, the incidence of constitutive IL-10 in sample 2 was $16.6 \%$ (Table 2), whereas that of inducible IL-10 was $50 \%$ (Table 2). It is not clear why neonate 1I showed constitutive IL-10 in sample 1 but not in sample 2, even though LPSinducible IL-10 was present in both samples. Most likely, such inconsistencies are reflective of the multi-parameter etiology of BPD and the complexities of postnatal development and maturation in preterm infants. However, it is clear that there is no evident association between the incidence of either constitutive or inducible IL-10 in sample 2 and that of BPD $(p=0.33)$.

The current studies also did not reveal a significant association between constitutive or inducible IL-10 and the incidence of BPD in the more mature neonates in group 2 (Table 3 ). Here, the incidence of BPD is low and only 2 out of a total of 14 neonates developed BPD. Constitutive IL-10 in sample 1 in neonates without BPD was $2 / 12$ (Table 3, neonates $2 \mathrm{E}$ and $2 \mathrm{H}$ ) or $16.6 \%$. In the two neonates with BPD (Table 3), this value was $50 \%$, but the numbers, as expected, were small. Incidence of inducible IL-10 in sample 1 from neonates without BPD was $50 \%$ (Table 3). Neither of the two patients who developed BPD (Table 3,2M and $2 \mathrm{~N}$ ) exhibited inducible IL-10 response. On d 4-7 of life, constitutive IL-10 in the neonates without BPD increased to $57.1 \%$, whereas this value in the neonates with BPD was at 100 (Table 3). Also, inducible IL-10 occurred in all (7 / 7) patients without BPD. In the two neonates with BPD, both constitutive and inducible IL-10 were detectable. These data clearly indicate a postnatal adaptation in maturation of both constitutive as well as inducible IL-10 gene expression.

IL-10 and gestational age. Previously, we demonstrated that LPS-induced IL-10 response of lung inflammatory cells from human preterm infants was a function of GA (9). The current analyses provide further support for the latter findings. We have proposed a model in which reduced or absent IL-10 may be associated with uncontrolled inflammation and consequently, risk for BPD (4). Because an important risk factor for BPD is prematurity itself, it may prove difficult to decipher whether the relationship between BPD and IL-10 is direct or indirect; through IL-10's relationship with GA: smaller infants have less IL-10 and increased risk for BPD. In this study, however, we separated the two aspects of IL-10 gene expression into constitutive and inducible components.

Table 5 summarizes the incidence of constitutive and inducible IL-10 across GA. The incidence of constitutive IL-10 on d $1-3$ is $22 \%$ (4/18) in group 1, which is nearly identical to that observed in the more mature neonates in group 2 (21\% or 3/14). Thus, within $5 \mathrm{wk}$ of in utero development (comparing neonates born at 23-27 wk, to those born at 28-34 wk of gestation), there is no associated increase (maturation) in constitutive IL-10 (Fig. 2). The latter conclusion assumes that there are not significant differences in the perinatal histories of the neonates born at 23-27 versus those at 28-34 wk of gestation. Careful survey of their histories is in fact consistent with this assumption (Table 1).

In contrast, the incidence of inducible IL-10 on d 1-3 within the same period (transition from 23-27 to 28-34 wk of gestation) increased from $27 \%$ (5/18) to $42 \%$ (6/14), suggesting that in utero development is accompanied by maturation of inducible IL-10 gene expression (Table 5 and Fig. 2). With the exception of constitutive IL-10 production in the 23-27

Table 5. Summary of numerical and percentile values for the incidence of "constitutive" and "inducible" IL-10

\begin{tabular}{ccccccccc}
\hline & $23-27$ & $w k$ & & $28-34$ & $w k$ & & \multicolumn{2}{c}{ Term } \\
\cline { 2 - 3 } \cline { 8 - 9 } Gestation DOL & S1 & S2 & & S1 & S2 & & S1 & S2 \\
\hline Constitutive percentile & $4 / 18$ & $4 / 17$ & & $3 / 14$ & $6 / 9$ & & $4 / 4$ & $4 / 4$ \\
& $(22)$ & $(23)$ & & $(21)$ & $(66)$ & & $(100)$ & $(100)$ \\
Induction percentile & $5 / 18$ & $8 / 17$ & & $6 / 14$ & $9 / 9$ & & $4 / 4$ & $3 / 4$ \\
& $(27)$ & $(47)$ & & $(42)$ & $(100)$ & & $(100)$ & $(75)$ \\
\hline
\end{tabular}

S1, sample 1 (d 1-3); S2, sample 2 (d 4-7) of life. Percentile values are in parentheses. 


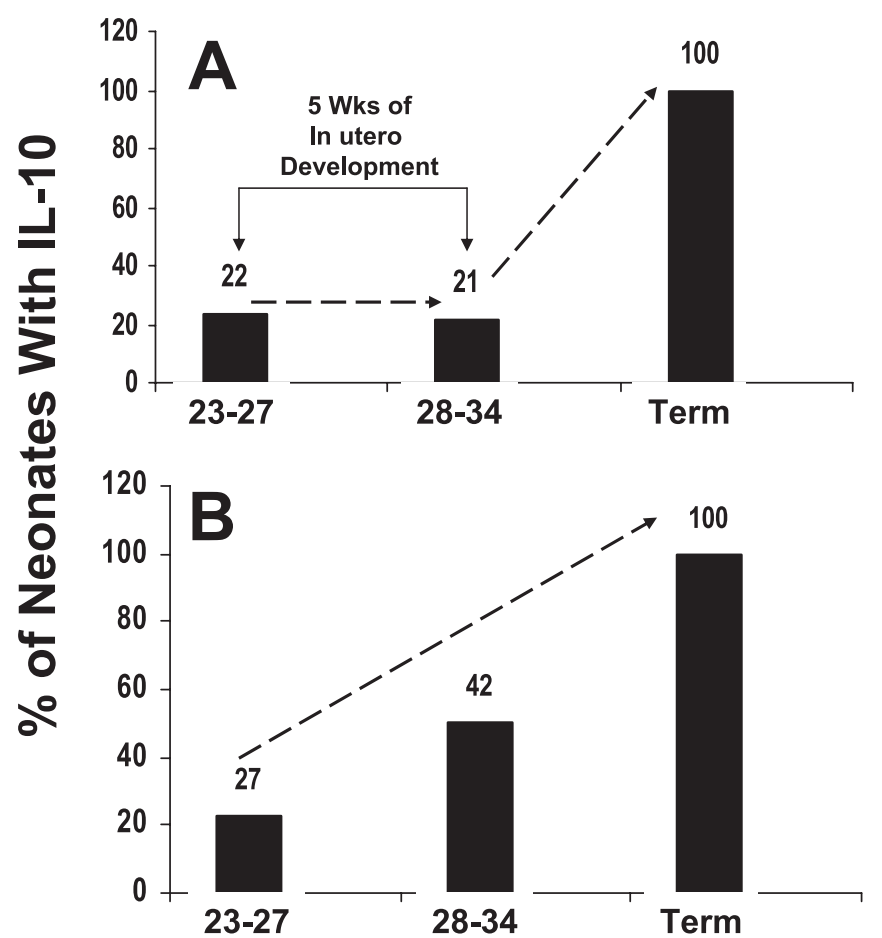

Figure 2. Constitutive $(A)$ vs Inducible $(B)$ IL-10 analysis in sample 1. Numbers above each bar represent percentage of IL-10 positive neonates. Within $5 \mathrm{wk}$ of in utero development (comparing neonates born at 23-27 wk, with those born at 28-34 wk of gestation), there is no significant change in the incidence of constitutive IL-10-positive neonates in preterm infants (23-27 vs 28-34 wk).

wk infants, postnatal adaptation as assessed by differences in sample 1 versus sample 2 occurred in inducible and constitutive IL-10 for both groups (Table 5). As a point of comparison, we also examined the profile of both constitutive and inducible IL-10 production in term neonates with meconium aspiration syndrome (Table 4). As expected, both constitutive and inducible IL-10 production, in both sample 1 and 2 was at $100 \%$, indicating that both aspects of IL-10 gene expression undergo in utero maturation. We could not explain why in the term neonate designated " $B$ " there was no inducible IL-10 on d 4-7 of postnatal life (Table 4). Nevertheless, the sum of these analyses argues strongly that in utero maturation of the IL-10 pathway in preterm neonates is in large part due to acquisition of the ability to respond to LPS (i.e. inducibility) (Fig. 3).

Constitutive IL-10 and antenatal inflammation. The underlying cause of constitutive IL-10 production in lung inflammatory cells is not clear. IL-10 production occurs in response to activation of the pro-inflammatory cascade, and serves the purpose of controlling it. Thus, constitutive IL-10 expression may presumably reflect perinatal stimulation of the inflammatory response, perhaps even in utero. Most, if not all, preterm deliveries are associated with infection and/or inflammation of fetal/maternal membranes. Therefore, if due simply to the latter, most infants in our study would be expected to present some degree of constitutive IL-10 production. This was not observed. Instead, only a limited number of infants, particularly in the 23-27 wk gestation group showed constitutive IL-10 production (Tables 2 and 3). This number re-

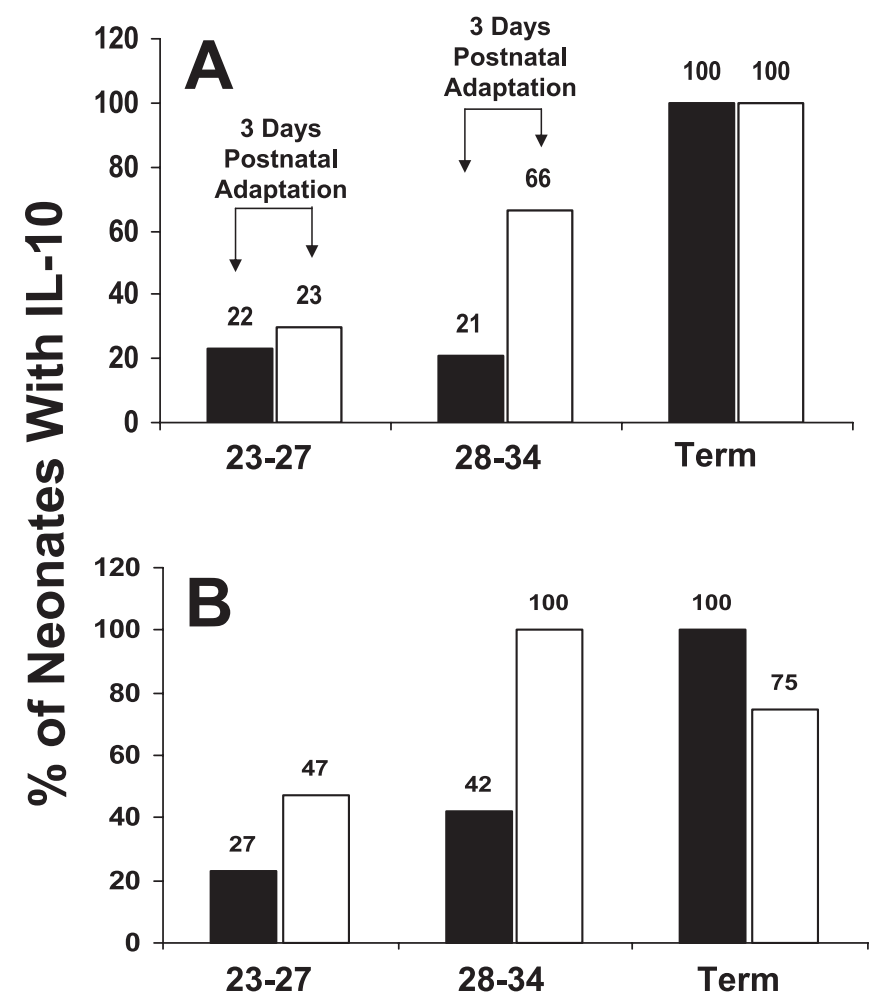

Figure 3. Constitutive $(A)$ and inducible $(B)$ IL-10 in sample 1(filled bars) vs sample 2 (empty bars) in premature and term infants. Numbers above each bar represent percentage of IL-10 positive neonates.

mained constant between less mature neonates of 23-27 wk gestation versus those of mature age of 28-34 wk. Thus, these findings argue against uniformity in maturation of IL-10 response, and instead suggest the presence of at least two groups of neonates; those with and those without a mature IL-10 response mechanism. The latter interpretation is consistent with our previous findings (9) and may likely reflect specific inter-individual genetic variations in IL-10 gene regulation.

Regulation of IL-10 is complex and the genetic mechanisms underlying the observed interindividual variability in IL-10 production are only beginning to emerge. Also, there are genetic variations in the $5^{\prime}$-flanking region of the IL-10 gene that may account for the response to different stimuli. Interindividual differences of LPS-stimulated IL-10 production have been found to be related to single-nucleotide polymorphisms (SNP). For example, carriers of the IL-10 "G" microsatellite with 22,24 , or 26 dinucleotide repeats, linked with the $-1087 \mathrm{G}$ SNP, exhibited the highest levels of IL-10 gene expression (12). Based on our findings, a systematic molecular genetic analysis of the potentially relevant polymorphisms, associated with interindividual variabilities among the very immature preterm infants appears to be well rationalized and may reveal important information. Furthermore, an important recent observation relates to IRAK1, a kinase downstream of Toll-like receptor signaling that is essential for LPS-induced IL-10, but not pro-inflammatory cytokines (e.g. IL-8 or TNF$\alpha)$. IRAK1 is constitutively activated in peripheral blood mononuclear cells from patients with atherosclerosis (15). Whether IRAK1 is present or activated in lung inflammatory 
cells from premature infants is an intriguing possibility that requires further investigation.

Caveats and conclusions. The literature on the expression of IL-10 in the lungs of preterm neonates is limited. McColm et al. (16) examined the presence of IL-10 in TAF from 17 neonates who were born at $\leq 29$ wk of gestation. IL-10 was readily detectable in early TAF samples from these ventilated infants, nine of whom developed BPD. Other investigators have found absent or irregular secretion of IL-10 (17). With the exception of the current study and our earlier report (9), studies on lung IL-10 gene expression in preterm infants have been entirely limited to measurement of the cytokine carried out directly in TAF, and therefore subject to variabilities that preclude quantitative results. In contrast, our ex vivo explant cultures could reliably be controlled based on cell number. Another noteworthy aspect of the current work is that despite significant variabilities in the quantity of IL-10 expressed in various samples (Tables 2 and 3), our analyses have been based entirely on presence or absence (i.e. + or -) of IL-10, rather than quantity in any given sample. Whether different levels of IL-10 correlate with clinical status or severity of lung disease is a worthwhile future analysis that requires a larger number of enrollees.

One potential limitation of the current study is the use of a mixed population of inflammatory cells. However, this limitation does not alter the overall interpretations of the data as conducted in the previous and the current studies. By careful analysis of lung cell profiles, we showed previously that the major inflammatory cell type recovered from the TAF that is responsible for production of both TNF- $\alpha$ and IL-10 is the lung macrophage (9). In summary, the observations made in the current study clearly suggest a link between the early presence, within the first $3 \mathrm{~d}$ of life, of constitutive IL-10 production and the incidence of BPD in neonates born at 23-27 wk of gestation. Analysis of IL-10 gene expression as carried out in this study clearly shows that whereas in utero maturation of IL-10 production is predominantly related to its inducibility, protection from BPD appears to be related to IL-10 constitutive production, suggesting that the relationship between IL-10 and incidence of BPD may not be simply due to the relationship between IL-10 and GA. Importantly, the data implicate a rather complex mechanism of IL-10 gene expression whose various components may differentially affect both maturation and defence against inflammation during lung injury. Particular attention should be paid to what in this and other reports is referred to as constitutive IL-10 gene expression. It is self-evident that at some point before the time of obtaining the samples, the latter was induced by, in most cases unknown factors. Since preterm labor and delivery are intractably linked with maternal/fetal inflammation, positive constitutive IL-10 may distinguish a select group of neonates with early or precocious maturation of IL-10 response mechanisms in utero. We propose that the latter phenomenon underlies the relative protection to BPD in the very premature neonates of 23-27 wk GA. A corollary to this concept is that neonates who gain "inducibility" only postnatally, but are negative for constitutive IL-10 production are at higher risk for developing BPD.

Acknowledgments. The authors thank the nurses, respiratory therapists, and other personnel of the neonatal Intensive Care Unit at LAC+USC Medical Center.

\section{REFERENCES}

1. Jobe AH, Bancalari E 2001 Bronchopulmonary dysplasia. Am J Respir Crit Care Med 163:1723-1729

2. Northway WH, Rosan RC, Porter DY 1967 Pulmonary disease following respiratory therapy of hyaline-membrane disease. Bronchopulmonary dysplasia. N Engl J Med 276:357-368

3. Jobe AJ 1999 The new BPD: an arrest of lung development. Pediatr Res 46:641-643

4. Jones CA, Cayabyab RG, Kwong KY, Stotts C, Wong B, Hamdan H, Minoo P, deLemos RA 1996 Undetectable IL-10 and persistent IL-8 expression early in hyaline membrane disease: a possible developmental basis for the predisposition to chronic lung inflammation in preterm newborns. Pediatr Res 39:966-975

5. Donnelly RP, Dickensheets H, Finbloom DS 1999 The interleukin-10 signal transduction pathway and regulation of gene expression in mononuclear phagocytes. J Interferon Cytokine Res 19:563-573

6. Riley JK, Takeda K, Akira S, Schreiber RD 1999 Interleukin-10 receptor signaling through the JAK-STAT pathway. Requirement for two distinct receptor-derived signals for anti-inflammatory action. J Biol Chem 274:16513-16521

7. Staples KJ, Bergmann M, Barnes PJ, Newton R 2000 Stimulus-specific inhibition of IL-5 by cAMP-elevating agents and IL-10 reveals differential mechanisms of action. Biochem Biophys Res Commun 273:811-815

8. Asadullah K, Sterry W, Volk HD 2003 Interleukin-10 therapy-review of a new approach. Pharmacol Rev 55:241-269

9. Blahnik MJ, Ramanathan R, Riley CR, Jones CA, Minoo P 2001 Lipopolysaccharide-induced tumor necrosis factor-alpha and IL-10 production by lung macrophages from preterm and term neonates. Pediatr Res 50:726-731

10. Shennan AT, Dunn MJ, Ohlsson A, Lenox K 1988 Abnormal pulmonary outcomes in premature infants: prediction from oxygen requirement in the neonatal period. Pediatrics 82:527-532

11. Kwong KY, Jones CA, Cayabyab R, Lecart C, Stotts CL, Randhawa I, Ramanathan R, Khuu N, Minoo P, deLemos RA 1998 Differential regulation of IL- 8 by IL- $1 \beta$ and TNF $\alpha$ in hyaline membrane disease. J Clin Immunol 18:71-80

12. Rieth H, Mormann M, Luty AJ, Assohou-Luty CA, Roupelieva M, Kremsner PG, Kube D 2004 A three base pair gene variation within the distal 5'-flanking region of the interleukin-10 (IL-10) gene is related to the in vitro IL-10 production capacity of lipopolysaccharide-stimulated peripheral blood mononuclear cells. Eur Cytokine Netw 15:153-158

13. Suarez A, Castro P, Alonso R, Mozo L, Gutierrez C 2003 Interindividual variations in constitutive interleukin-10 messenger RNA and protein levels and their association with genetic polymorphisms. Transplantation 75:711-717

14. Schmitz ML, Mattioli I, Buss H, Kracht M 2004 NF-kappaB: a multifaceted transcription factor regulated at several levels. Chembiochem 5:1348-1358

15. Huang Y, Li T, Sane DC, Li L 2004 IRAK1 serves as a novel regulator essential for lipopolysaccharide-induced interleukin-10 gene expression. J Biol Chem 279:51697-51703

16. McColm JR, Stenson BJ, Biermasz N, McIntosh N 2000 Measurement of interleukin 10 in bronchoalveolar lavage from preterm ventilated infants. Arch Dis Child Fetal Neonatal Ed 82:F156-F159

17. Jonsson B, Li YH, Noack G, Brauner A, Tullus K 2000 Downregulatory cytokines in tracheobronchial aspirate fluid from infants with chronic lung disease of prematurity. Acta Paediatr 89:1375-1380 